\title{
Investigating the Impact of Community Based Health Insurance Scheme among the Rural Dwellers of Sokoto State Nigeria
}

\author{
Garba Ibrahim Tanko \\ Azhar Harun \\ Universiti Utara Malaysia Universiti Utara Malaysia \\ Email.Garibtan65@gmail.com / azharHarun@uum.edu.my \\ Abdullahi Hassan Gorondutse \\ Salihu, Abdulwaheed A \\ Ibrahim Badamasi University, Lapai, Nigeria \\ Email: adelabusalihu21@gmail.com / ahgdutse@gmail.com
}

\section{Doi:10.5901/mjss.2015.v6n1s1p145}

\begin{abstract}
Health protection seen as a method of conveying the monetary risk connected with the variety of singular's human services used by pooling expenses over the long run through prepayment and other individuals with risk pooling. The health protection approach seeks to evacuate financial boundaries to gaining a satisfactory level of health care and requires the affluent to experience the expense of support of the sick; the element of cross-subsidy is crucial. Therefore, the objective of this study was to carry out Data gathering in respect to Data screening and preliminary analysis in related to investigating the impact of community based health insurance scheme among the rural dwellers of Sokoto state Nigeria. The study employed convenience sampling techniques, equally the exercises was carried in order to suit the supposition of multivariate analysis. In view of that, an appraisal of Data is missing, identify univariate and multivariate outlier and lastly, skewness and kurtosis were checked. In addition, factor analysis through Exploratory Factor Analysis (EFA) was also carried out. Similarly, all the exercises were prepared in Statistical Package for Social Science (SPSS) software version 18, and the preliminary analysis revels convinced that the data fulfill the condition of multivariate analysis. The findings will give an insight into further analysis its hope to provide an understanding of how and why this may be diversified in a perspective rising environment.
\end{abstract}

Keywords: Community based health insurance, data selection, Sokoto, rural dwellers and Nigeria.

\section{Introduction}

The significance of data, preliminary in analysis cannot be over quantified as it is very indispensable in social science research (Gorondutse \& Hilman, 2014; Hair, Hult, Ringle, \& Sarstedt, 2013). Missing data happen when a respondent either deliberately or accidentally fails to respond to one or more questions (Hair et al., 2013). For that reason, the value and the evocative conclusion of the analysis more less depend on the initial data screening (Gorondutse \& Hilman, 2014;; Maiyaki \& Moultar, 2011). Unfortunately, this basic preliminary exercise is more often than not being unobserved by researchers perhaps due to the weight attached to it (Hair et al., 2010, 2013; Maiyaki \& Mouktar, 2011).

However, leaving this segment of data preliminary would absolutely have an effect on the result on the result value and /or the suitability of the types of analysis required. Although according to Tabachnic and Fidell (2007) the best way of insuring precision is all the way through proof reading of the original data vis-à-vis the computerized data file. Conversely, with big data set, proof reading is complicated or even unattainable (Maiyaki \& Mouktar, 2011). For this reason, there is need to investigate data through descriptive statistics using computer software. In this way, all the unseen errors that are not easily experiential would be exposed (Gorondutse \& Hilman, 2014; Hair et al., 2010, 20130).

In addition, the authors observed that by preparing data assessment, researcher have at least two essential advantages (Hair et al., 2010). (1), whole indulgent of the inter-associations among the constructs and as a result facilitates clear explanation of the output. (2), capability to gratify the postulations of multivariate data analysis which is more difficult than in univariate analyses. On a final note, this study examined issues related to data screening and preliminary analysis in order to have a free error Data as recommended by (Gorondutse \& Hilman, 2014;; Hair et al., 2010). 


\section{Literature Review}

According to Linder, S. H., and B. G. Peters. (1988) that policy process stretches out to both the methods or mechanisms through which policy objectives are given impact, and to the objectives themselves since objective explanation inexorably includes contemplations of practicality, or what is reasonable or conceivable to attain in given conjunctures or conditions given the means at hand. This involves that the policy process by this scholar, means efforts made by government to modify aspects expressions of their own plans or social conduct with a survey to carry out new initiatives in governance. Anderson, Chris, (2005) posits that policy as a affirmation of intent and is carried out as a procedure or protocol, Therefore, from the views of this scholar's policy process is realized to be the action plan of government that is what is meant to suffice for the people in countries that are thought to be of assistance to the people general well being which may include adding new policies such as in Health (CBHIS), Education, Security, and socioeconomic well being of the citizenry. Health insurance is not for its own sake, but for enabling an insured Person to need health care services when in need. Health insurance is of little value if the supply position is light. The state could take on an active part in matching up the provision of health Services.

Health insurance is not for its own sake, but for enabling an insured Person to need health care services when in need. Health insurance is of little value if the supply position is light. The state could take on an active part in matching up the provision of health Services. Presently, most CBHI schemes have little or no legal standing which tends to produce some hesitation in the mines of the public about the continuity of schemes. Providing legal status may motivate confidence among the local community, resulting in higher membership. Another way in which government could support the schemes is in providing some insurance mechanism against risks. CBHI schemes might be successful in insuring against individual Health risks and not for related risks. In the event of catastrophic risks, these schemes tend to crash. Such risks can best be insured against through alternate public financing. State could aid in diversifying risk through social reinsurance (Dror and Preker 2002). ). Like user fees, insurance should be visualized as a measure that complements other steps providing health security for the low-income families. More generally, insurance is only one of the Risk management strategies available to the people. However, the state could improve on its provision of providing loans and other credit facilities like CBHIS and other organizations in order to make them financially sound so they will be able to carry out their desired objectives. Similarly, health security needs to be incorporated with other government programs proposed at building income and health protection for the poor and needy in the rural communities. Also the policy makers should take into consideration the economic capacity of the rural dwellers when deciding on payment of premium in the establishment of CBHIS, here the policy makers should give the rural dwellers free hand to agree on what they can afford to pay as premium in CBHIS for the sake of sustainability of the scheme.

Health security is progressively being distinguished as basic to any poverty reduction strategy. While the goal of poverty stays of focal concern, there has been a movement of centre far from poverty reduction in kernel of social risk administration. This is so on the grounds that of developing energy about the role risk play in the lives of poor people (Holzmann and Jorgensen 1999), and in view of a solid positive connection between health and poverty reduction, especially at low wage levels (Morrisson 2002, CMH 2001). The state in most developing nations had not had the capacity to satisfy health services needs of its poor populace. Contracting budgetary backing for health care services, wastefulness in the broad daylight health provision, the unsuitably low nature of public health services, and the resultant burden of user-fees is reflective of state's powerlessness to help poor people. In the last decade, the "health care crisis" prompted the rise of CBHIS in diverse areas of developing nations, especially in sub-Saharan Africa (Wiesmann and Jütting 2001, Preker et al. 2001, ILO 2002). The achievement of community based micro-credit plans may have additionally helped the rise of community based health activities intended to enhance the right to gain access through risk and resource sharing (Dror and Jacquier 2000, Brown and Churchill 2000, ILO 2000).

According to Lin and Gibson, (2003) the preparation of health policy requires a set up competing rationalities: political, technological and cultural. "Stronger emphasis should be placed on translating knowledge into action to improve public health by bridging the gap between what is experienced and what is really being managed" (WHO, 2004: XV). Health policy makers in the Sub-Saharan Africa (SSA) countries face major public health problems such as endemic diseases, which include Tuberculosis, Malaria, cholera, HIVIAIDS. Some other long standing health conditions include child mortality rate and maternal mortality rate are increasing, including the impact of inadequate nutritional intake among the children in rural areas. The macroeconomic measures, implanted in neoliberal belief system, pointed fundamentally at declining government spending to address budgetary shortfalls, including expense recovery instruments through user fees (Akin J, Birdsall N, de Ferranti D. 1987).

The experience of community-based health insurance dates back to the Alma-Ata Conference in 1978, when "several" health minister present at the Conference made a commitment to introduce reform in health organizations and 
extend universal primary health care to poor people in their different states. Only they fail to accomplish this noble intention due to absent of political will and inadequate resources. Thus, the Bamako Initiative promoted the entry of user fees, commissions and the involvement of communities in managing primary care in Africa to reach universal coverage (Gilson L, Kslyalya D, Kuchler F, Lake S, Oranga H, Oueno M.). Nevertheless, these policies were progressively abandoned because of the policy of introducing user fees succeeded in ejecting the most vulnerable group in their communities. So as option to user fees community-based health insurance, which is voluntary, non-revenue driven protection based on the ethic of mutual support emerged as a means of providing health care to the people (Atim C, Criel B, Basara R, Blaise P, Waelkens MP 1998, 2004). CBHIS main concerned is to bridge the gap over in access to health services and to outfit government managed savings between individuals secured by the formal health social security and the individuals who need to yield for their medical care out of their own pocket. The World Bank claims that CBHIS is very efficient in protecting many low -income people against the high cost of sickness (PrekerAS, Carrin G, Dror DM, Jakab M, Hsio W, Arhin D.2011). Therefore, the process of policy implementation and political of government play a very important role to actualization of universal health care coverage (UHC) through community based health insurance scheme in Nigeria and in other Sub Saharan African countries.

Health is a significant form of social capital, and there exist a substantial agreement in the literature on the relationship between health and economic growth through relationship between capability and need. The maintainability and suitability of the nation's economic and social growth depend mainly on the vibrant health care arena of the country. A simple channel through which health affects social development is by improving living conditions. As living conditions improve, it's required that the human lifespan is going to increase and vice-versa. Verifiable data has recorded that, within poor areas, increase in life expectancy is strongly related with the growth in productivity and income. Hence, economic growth, which generated the economic development, is related to output per individual. Besides, according to Eshiobo et al (2007) Recognized that health is a significant section of the country's socioeconomic development of good health does not just contribute to better quality of life, but is also absolutely necessary for a firm labour force for the foundation and maintenance of the nation's wealth. Virile labour strength is needed in developing countries which depend on primary products mainly agricultural goods, raw materials and so forth Hence, individuals can invest their best by contributing to the development and economic growth if economically empowered through health status. The economic meltdown in modern economics, which followed the oil shocks of 1973 and 1979 ultimately led to a profound life recession that left many of the nations in the area almost in total confusion. Great national debts, among other components, force most of them to embark on economic reform bills. One stage of the reforms includes the introduction and implementation of structural adjustment programs (SAP) whose main components include trade liberalization, currency devaluation, and cuts in government spending.

The most hit by these reforms is the social sectors of the Nigerian economy, particularly health and education by the outcome of economic decline and the economic reform programs were performed. Besides, not only these measures slow down the pace of health development in most African countries; they also weakened their systems to the point of near collapse (WHO, 2002). According to the WHO World Health Report (1998) "poverty is the main reason why babies are not vaccinated, why clean water and sanitation are not provided, why curative drugs and other treatment are unavailable and why mothers die in childbirth. It is the underlying cause of reduced life expectancy, handicap, disability and starvation. Poverty is a real contributor to mental illness, stress, suicide, and family disintegration.

The seventy percentage of the total population in Nigeria still lives in rural areas. These rural areas are blessed with abundant mineral resources, most of which have not been exploited. The few whose resources appear explored are living with extensive damage to the rural setting (Agbonoga, 1998). In Nigeria over $80 \%$ of these rural communities are involved in agricultural quest and the bulk of them are still using unscientific methods characterized with low output. Aloba (1998) and Akinola (1997) affirm that only a few roads in the rural areas are partially motor able during the short peak time of the dry season. This will seriously affect the removal of agricultural production to urban centers. As per World Health Report (2005), forty-four countries of the WHO African Region spend less than $15 \%$ of their national annual budget on health; 29 national governments used less than $\$ 10.00$ for every individual for every year; fifty percent of the sum expenditure on health in 24 nations hail from government sources; the prepaid health financing mechanisms incorporate just a miniscule size of communities in the Region; private expenditure constituted over $40 \%$ of the sum use on health in 31 nations; out-of-pocket expenses constitute fifty percent of the private health expenditure in 38 nations. This is to state that there is the high rate of out-of-pockets spending on accessing health care among the rural dwellers in Nigeria which if persistent could possibly push them into poverty.

Rather than social protection actualized in Germany, current development in health insurance schemes "in Africa" have taken the type of community openings of rather little size insurance scheme that are community built with voluntary mobilization. They have either been started by Ngos, health facilities, cooperatives or nearby local communities and 
might be owned and run by any of these associations (Atim 1998, Criel 1998b). The suitability of a CBHIS partly depends on outside determinants that can hardly be influenced by the schema such as a country's legal and policy framework (Criel, B 1998b). But, however, the design of the scheme and its functioning as well as community support are important factors of sustainability. The best size of a scheme to ensure sustainability and adequate risk pooling and possible edge levels of membership needed to realize large economics of scale are not yet known (Debaig, G. /CIDR 1999). There is no known general rules for the minimum size can be given either, because the proper size of the risk pool largely depends on the value and nature of risks between the insured. . The benefit package might as well incorporate essential services towards health care necessities and should be affordable to the rural dwellers. While health insurance funds can replace public subsidies and outside help just to a constrained degree in low-income countries, the real fees of the health benefit package ought to be considered when the premium is estimated (Musau, S. 1999). Community-based health insurance is a guaranteeing new instrument to better health system for rural dwellers in low-income nations, especially in SSA (Creese A, Bennett S, 1997). Therefore, economic enhancement activities among the rural dwellers will contribute to the sustainability and growth of community based health insurance scheme.

According to Jarry Gana (1987) argues "social gathering is the procedure of pooling together, harnessing completing and using potential human asset with the end goal of improvement. It is the process whereby people are made familiar with the resources available to them, and are likewise inspired and energized to "collectively" use such resources for the improvement of their profound and material conditions of living." Rana (1995a:5) Mobilization may be defined as "the process of putting aside poor people, marginalized and disenfranchised segments of social order create and administer their association and in this way partake in decisions influencing their day-to -day survival through the utilization of their own ingenuity." Cohen, (1996) argues that mobilization "as a process of employing a large number of people in joint action for achieving societal goals through self-reliant efforts. Therefore, for the sustainability of the implementation of community based health insurance scheme the rural dwellers need to mobilize and well inform about the various advantages of the community health insurance scheme by informing them about the health package and also to educate them on the need for them to contribute small amount of money which will required to be paid by the enrollees as agreed by them and also by informing them that they are going to be the once who are going to be in charge of the scheme in their various locality. According to Delgado-Gaitan, Concha (2001), community mobilization is a process which is encouraged by a community itself, or by others, that is planned, ran out, and measured by the community's individuals, groups, and organizations on a participatory and sustained basis to improve the health, hygiene and education so as to enhance the overall standard of living among the rural dwellers. So the government, traditional rulers, and the various stakeholders have a tremendous role to play in achieving effective mobilization of the rural dwellers on the importance of enrolling in community based health insurance scheme.

\section{Methodology}

In this section the data assessment was carried out with the aid of both descriptive and inferential statistics using SPSS 81 version software. For example, simple descriptive statistics, Mahalanobis distance, correlation analysis were engaged. In addition, the sample of the study derived from the rural dwellers of Sokoto state Nigeria. Convenience sampling design was used to collect data.

\section{Results and Discussion}

This section present result and discussion, out of the 800 copies of questionnaires circulated, a sum of 700 copies were finally completed, given a response rate of $80 \%$. A reasonable good response rate achieved which is above expected rate of response and as a result of the researcher's persistence for on the stain achievement of the questionnaire. Furthermore, the researcher used a technique of motivation by providing a form a pen, which to a great degree encouraged a great number of the participants to take part in the exercise. Moreover, in trying to address the issues of preliminary analysis, it result in deleting one hundred and seventeen copies of questionnaires and consequently not painstaking and not eligible to be part of the analysis. Thus, a sum of 583 copies of questionnaires was live in order to continue with the preliminary exercise.

The descriptive analysis reveals that $22.0 \%$ were Female heads of household, Male head household, $38.1 \%$, were Wives, 13.9\%, were Grandmother, 1.3\%, were Representative of household, 24.2\%. Descriptive statistics show that the respondents male head of household participated more, follow by the representative of household, than follow by the female head household, follow by wives and lastly by grandmother. It can be clearly seen that majority of the respondents are the male head household follow by the others. While the descriptive statistic reveals that $35 \%$ were not the main 
income earner among the respondents, while $64.4 \%$ were household main Income earners in the household.

The descriptive statistics on the Number of people living in the household it reveals that, 1-5 36.5\%, $6-1544.1 \%$, $16-2511.6 \%, 26-354.1 \%$, while 35 and above are 3.7\%. Similarly, the descriptive statistics reveals that from the age group 0 - 18 6.4\%, 19 - 25 54\%, 25 - 35 29.3\%, 35 - above 9.6\%. Here, respondent in age group from $19-25$ years participated actively in the survey, follow by those in age group of $25-35$ years with $29.3 \%$ meaning that in this survey middle age group participated more than the young and old. Furthermore, the descriptive statistics on the sex of the respondent reveals that female respondent were $80.7 \%$, while male respondent were $80.6 \%$. This means that both sex participated actively in the survey.

Furthermore, the descriptive statistics on highest educational status the analysis reveals that respondents with university degree were $100 \%$, follow by respondent with vocational college certificate were $99.6 \%$, follow by respondent with primary school certificate were $98.7 \%$, follow by those respondent who only attended secondary school were $99.1 \%$, and then lastly, those respondent who have never attended school were $53.8 \%$.

While, the descriptive statistics of the Occupation of the respondents were those Unemployed $76.5 \%$, follow by those respondents who are engage in petty trading were $14.6 \%$, follow by those respondents who were Self employed professional were $4.3 \%$, follow by those respondents who were famers were $4.1 \%$, and then lastly those respondents engage in the private sector were $3 \%$. Therefore, it means that respondents who are unemployed participated more in the survey, follow by those respondent doing petty trading, self employed professionals, farmers and lastly those in the employed in the private sector.

Based on above, it could be summarized that the respondents who participated in the research provided adequate variance regarding their backgrounds. Hence, the data used in the study were provided by respondents from diverse economic backgrounds (see Table 1).

Table 1. Summary of respondents (see Table 1)

\begin{tabular}{|c|c|c|c|}
\hline$S / N$ & Items & Frequency & Percentage \\
\hline \multirow[t]{8}{*}{1} & What is your status in your household & & \\
\hline & Female heads of household & 154 & 22.0 \\
\hline & Male head household & 266 & 38.1 \\
\hline & Wives & 97 & 13.9 \\
\hline & Grandmother & 9 & 1.3 \\
\hline & Representative of household & 169 & $\begin{array}{c}1.0 \\
24.2\end{array}$ \\
\hline & Are you the main income earner in your household? & $\begin{array}{l}109 \\
249\end{array}$ & $\begin{array}{l}24.2 \\
35.6\end{array}$ \\
\hline & Yes & 249 & 35.0 \\
\hline \multirow[t]{4}{*}{2} & No & 440 & 62.9 \\
\hline & How many people live in your household & 255 & 36.5 \\
\hline & 1 - 5 & 308 & 44.1 \\
\hline & $6-15$. & 81 & 11.6 \\
\hline \multirow[t]{6}{*}{3} & $16-25$ & 29 & 4.1 \\
\hline & $26-35$ & 26 & 3.7 \\
\hline & 35 - above & 45 & 6.4 \\
\hline & How old are you & $3 / 9$ & 54.2 \\
\hline & $0-18$ & 205 & 29.3 \\
\hline & $19-25$ & 60 & 9.6 \\
\hline \multirow[t]{5}{*}{4} & $25-35$ & 61 & 8.6 \\
\hline & 35 - above & $\begin{array}{c}61 \\
373\end{array}$ & 0.1 \\
\hline & Sex & 311 & $\begin{array}{l}53.4 \\
44.5\end{array}$ \\
\hline & Male & $\begin{array}{c}311 \\
3\end{array}$ & .4 \\
\hline & Female & 3 & .4 \\
\hline \multirow[t]{3}{*}{5} & What is your highest education status & 3 & .3 \\
\hline & $\begin{array}{l}\text { Never attend school Primary school } \\
\text { Secondary Vocational college }\end{array}$ & 29 & 4.1 \\
\hline & $\begin{array}{l}\text { Secondary Vocatıonal college } \\
\text { University or hiaher }\end{array}$ & 535 & 76.5 \\
\hline 6 & What occupation is vour maior source of income & 102 & 14.4 \\
\hline 0 & Famer Unemployed & 30 & 4.3 \\
\hline & Petty trading Self-employed professional & 3 & .4 \\
\hline 7 & Employed in the private sector & & \\
\hline
\end{tabular}




\subsection{Tests of Non-Response Bias}

Non-response has been defined as the mistake a researcher expect to make while estimating a sample characteristic because some types of survey respondents are under-represented due to non-response (Berg, 2002). It is well explain in the literature that "there is no minimum response rate below which a survey estimate is necessarily biased and, conversely, no response rate above which it never bias" (Singer, 2006, p. 641). However, no matter small the non response, there is a possible bias which must be investigated (Pearl \& Fairly, 1985; Sheikh, 1981), thus the need for conducting the non-response bias analysis for this study.

While as shown Table 2, respondents were categorized into two independent samples based on their response to the questionnaires regarding five main survey variables (Policy process, Economic growth, Scheme design, Mobilization and Impact of community based health insurance scheme on health services). The most common the standard ways to test for non-response bias in this research is to contrast the responses of those responded to the questionnaires distributed early before the end of April, 2014 and those who responded to the questionnaires distributed after April, 2014. Looking at the table below, it might be seen generally that range mean and standard deviation for early response and late response are distinctly diverse. The 2 tailed t test result (Table 3 shows that there is no significant disparity with respect to the early respondents and behind based on Policy process (t 1.084, $p<.075)$, Economic growth (t.002, $p<$ .300), Scheme design (t.001, $p<.002$ ), Mobilization (t.135, $p<.140$ ) and Impact of community health (t.044, $p<.060$ ). Therefore, based on the $t$ test results it can be fulfilled that there is almost no dissimilarity between the early participants and the late participants, and consequently no dilemma of non-response bias (see Table $2 \& 3$ ).

Table 2. Group descriptive statistics for early and late respondents

\begin{tabular}{|ll|c|c|c|c|}
\hline \multicolumn{2}{l}{ RESPONSE } & $\mathrm{N}$ & Mean & Std. Deviation & Std. Error Mean \\
\hline \multirow{2}{*}{ PROCESS } & 1 EARLY RESPONSE & 466 & 3.4077 & .52168 & .02417 \\
& 2 LATE RESPONSE & 233 & 3.4780 & .47423 & .03107 \\
\hline \multirow{2}{*}{ ECONOMIC } & 1 EARLY RESPONSE & 466 & 3.2501 & .76494 & .03544 \\
& 2 LATE RESPONSE & 233 & 3.4268 & .66311 & .04344 \\
\hline \multirow{2}{*}{ SDESGN } & 1 EARLY RESPONSE & 466 & 3.3569 & .65985 & .03057 \\
& 2 LATE RESPONSE & 233 & 3.5200 & .59451 & .03895 \\
\hline \multirow{2}{*}{ MOBILZ } & 1 EARLY RESPONSE & 466 & 3.5447 & .52046 & .02411 \\
& 2 LATE RESPONSE & 233 & 3.6080 & .53935 & .03533 \\
\multirow{2}{*}{ IMPACT } & 1 EARLY RESPONSE & 466 & 3.4271 & .78165 & .03621 \\
& 2 LATE RESPONSE & 233 & 3.5383 & .63273 & .04145 \\
\hline
\end{tabular}

Table 3. Independent samples T-test for equality of means Levens' Test for equality of variance

\begin{tabular}{|c|c|c|c|c|c|c|c|c|c|}
\hline & $F$ & Sig. & $\mathrm{T}$ & Df & $\begin{array}{l}\text { Sig }(2 \\
\text { tailed }\end{array}$ & \begin{tabular}{|c|} 
Mean \\
Difference
\end{tabular} & \begin{tabular}{|l|} 
Std. Error \\
Difference \\
\end{tabular} & $\begin{array}{l}95 \text { Confidence the } \\
\text { difference Lower }\end{array}$ & $\begin{array}{c}\text { Internal } \\
\text { Upper }\end{array}$ \\
\hline $\begin{array}{l}\text { Equal variance (Assumed) } \\
\text { PP } \\
\text { Equal variance (Not Assumed) }\end{array}$ & 2.865 & .091 & $\begin{array}{l}1.730 \\
1.786\end{array}$ & $\begin{array}{c}697 \\
505.37 \\
5\end{array}$ & $\begin{array}{l}.084 \\
.075\end{array}$ & $\begin{array}{c}07029 \\
0729\end{array}$ & $\begin{array}{l}.04063 \\
.03936\end{array}$ & $\begin{array}{l}.15006 \\
.14762\end{array}$ & $\begin{array}{l}.00948 \\
.00704\end{array}$ \\
\hline \begin{tabular}{|l} 
Equal variance (Assumed) \\
EG \\
Equal variance (Not Assumed)
\end{tabular} & 7.191 & .008 & 3.006 & $\begin{array}{c}697 \\
527.02 \\
3\end{array}$ & $\begin{array}{l}.003 \\
.002\end{array}$ & $\begin{array}{l}.17672 \\
.17672\end{array}$ & $\begin{array}{l}.05878 \\
.05606\end{array}$ & $\begin{array}{l}.15006 \\
.14762\end{array}$ & $\begin{array}{l}.06131 \\
.06659\end{array}$ \\
\hline $\begin{array}{l}\text { Equal variance (Assumed) SD } \\
\text { Equal variance (Not Assumed) }\end{array}$ & 4.509 & .034 & $\begin{array}{l}3.182 \\
3.295\end{array}$ & $\begin{array}{c}697 \\
509.39 \\
7\end{array}$ & $\begin{array}{l}.002 \\
.001\end{array}$ & $\begin{array}{l}.16313 \\
.16313\end{array}$ & $\begin{array}{l}.05126 \\
.04951\end{array}$ & $\begin{array}{l}.26376 \\
.26039\end{array}$ & $\begin{array}{l}.06249 \\
.06586\end{array}$ \\
\hline $\begin{array}{c}\text { Equal variance (Assumed) } \\
\text { MOBIL } \\
\text { Equal variance (Not ssumed) }\end{array}$ & .940 & .333 & $\begin{array}{l}1.496 \\
1.478\end{array}$ & \begin{tabular}{|c|}
697 \\
449.68 \\
6
\end{tabular} & $\begin{array}{l}.135 \\
.140\end{array}$ & $\begin{array}{l}.06323 \\
.0632\end{array}$ & $\begin{array}{l}.04227 \\
.04278\end{array}$ & $\begin{array}{l}.14622 \\
.14730\end{array}$ & $\begin{array}{l}.01976 \\
.02084\end{array}$ \\
\hline $\begin{array}{c}\text { Equal variance (Assumed) } \\
\text { IMPACT } \\
\text { Equal variance (Not Assumed) }\end{array}$ & 1.138 & . 287 & $\begin{array}{l}1.885 \\
2.021\end{array}$ & $\begin{array}{c}697 \\
558.80 \\
6\end{array}$ & $\begin{array}{l}.060 \\
.044\end{array}$ & $\begin{array}{l}.11123 \\
.11123\end{array}$ & $\begin{array}{l}.05901 \\
.05504\end{array}$ & $\begin{array}{l}.22709 \\
.21934\end{array}$ & $\begin{array}{l}.00463 \\
.00312\end{array}$ \\
\hline
\end{tabular}


The returned hand delivery questionnaire were serialized on top each questionnaire; this can help in identifying and distinguished the late and early respondent. The questionnaire has a code to make it easy to trace and check, in addition, the data were keyed into the SPSS accordingly.

\subsubsection{Coding}

The essence of coding is to make it easy for identifying the items, therefore, an effort was made while designing the questionnaire to ensure that all items had a number to help when keying in the data. The coding is based on the number and unique variable name. After that the code will be recorded in the code book containing all the constructs in the questionnaire.

\subsubsection{Editing Data}

The returned questionnaires were checked for incompleteness the questionnaire that was unanswered were discarded and marked as "blank". Similarly, questionnaires with a substantial number of items (for example25\%) left unanswered were all discarded, for a question with only two or three items left blank, the discussion is in the missing data section.

The wording of several items, as item

\subsection{Missing Data}

In view of the effect of missing data in the analysis, the researcher took preventive achievement right from the field of data collection in an effort to decrease their rate. On receipt of finished questionnaires, the researcher/research assistant rapidly checked from the beginning to end to make sure that all questions were properly answered. In box a participant unseen a question(s) he/she was instantly required to gently fill the questionnaire properly (Gorondutse \& Hilman, 2014; Maiyaki \& Moktar; 2011). Thus, this help significantly in decreasing the figure of missing data in the examination. Following putting the data into SPSS software, first round descriptive statistics was run to recognize whether or not there were missing data. The descriptive statistics exposed that two cases had significant missing values and seemed to be at random, and therefore, were removed from further analysis (Gorondutse \& Hilman, 2014;; Maiyaki \& Moktar, 2011). This is in line with the suggestion of Hair et al. (2010). That any case with more than $50 \%$ missing data should be removed as extensive as the sample sufficient (Gorondutse \& Hilman, 2014;; Maiyaki \& Moktar, 2011). Moreover, a process for treated missing data is to basically drop the case Tabachnic and Fiddel (2007) view that. In addition, the statistics information reveals that another one case had inconsequential Gorondutse \& Hilman, 2014;; missing values of 1 missing data is predominantly essential because PLS-SEM is very responsive to missing data, and as a result, it was adequately checked (Maiyaki \& Moktar, 2011). Additionally, PLS software does not run the data with missing values.

\subsection{Assessment of Outliers}

Apart from missing data, another significant step of data screening is the evaluation and handling of outliers, which are the excessive case scores that may likely have a considerable negative impact on the outcomes (Gorondutse \& Hilman, 2014;Maiyaki \& Moktar, 2011). Outlier cases typically have an uncommonly high or low value, a construct or a distinctive mixture of values across numerous constructs, which makes the examination stand out from the remaining (Bryn; 2010, Hair et al, 2010). Thus, using multivariate analysis may confirm the detection and handling of outliers consequently. Therefore, all the two; univariate and multivariate outliers were checked in this study. Univariate outliers were checked using SPSS by detecting cases with large z-score values. Hence, case with standardized z-score values of more than 3.29 is considered to be potential univariate outliers (Tabacnic \& Fiddle, 2007). Moreover, with respect to the suggestion of Tabachnic and Fiddle (2007) Mahanalobis Distance (D) was conducted to discover and deal with multivariate outlying cases (Hair et al., 2010). The method is to run Mahalanobis in the SPAA and then judge against the values with that of the Chi-square table (Tabachnick \& Fidell, 2007). Known that 49 items were adapted, representing the degree of freedom in the X2 table with $\mathrm{P}<0.001$, so the standard is 85.35 (Gorondutse \& Hilman, 2014;Tabachnick \& Fidell, 2007). This means that any figure with a Mahalanobis Distance of 85.35 and above, and consequently, multivariate outlier and were removed from contention in the analysis. 


\subsection{Normality Test}

Normality is the mainly significant postulation in multivariate analysis (Tabachnick \& Fidell, 2007; Hair et al., 2010). It deals with the nature of data circulation for an individual regularly construct and its association with normal distribution (Gorondutse \& Hilman, 2014;Tabachnick \& Fidell, 2007). Furthermore, when the final aim of research is making an inference, then screening for normality is a significant step in nearly all multivariate normality were examined. The preliminary test of normality reveals that there was a sign of non-normality, which was revealed by calculating the Z-score values for each item. As a few cases had a Z-value of more than +-2 and broaden above the variable range of $<2$ and $<7$ respectively. For instance, skewness values are less than 2; similarly, the kurtosis values, are less than 7 . Perhaps this is in line with the examination improves outcome, and that normality should be re-checked after normalization (Maiyaki \& Moktar, 2011).

In knowing that homoscedasticity test is related to the assumption of normality, if the data are fairly normal, then the relationship between the variables is assumed to be homoscedastic and thus, hoteroscedasticity is absent (Tabachnick \& Fidell, 2007). The fact that, both the multivariate and univariate normality are confirmed in this study, it could be concluded that, the assumptions of homoscedasticity, and the absence of heteroscedasticity are achieved.

\subsection{Multicollinearity}

Multicollinearity is a predicament that happens when the independent variables are extremely interrelated to as high as 0.9and above (Tabachnick \& Fidell, 2007). As soon as two or more or above constructs are excessively interrelated, they enclose unnecessary information, and for that reason, not all of them are required in the same analysis, since they enhance or increase the size of error terms, and thus, grow weaker the analysis (Gorondutse \& Hilman, 2014;Maiyaki \& Moktar, 2011). If the Multicollinearity problem is detected, it can be resolved by deleting the offending variables(s). To screen for Multicollinearity, Variance Inflation Factor (VIF) and tolerate level were examined via regression results from the SPSS. The general rule of the cutoff points is that the VIF and the tolerance values should not exceed 10 and be supposed to not be less than 0.10 , respectively (Hair et al., 2010). From the table 4it clearly shown that tolerance ranges between $0.693-0.876$ considerably $>0.10$. Similarly, VIF ranges from 1.141-1.443, and thus, is good enough as being $<10$ (Tabachnik \& Fidell, 2007). Consequently, it is concluded that there is no multicollinearity problem among the exogenous variables.

To re-confirm the absence of multicollinearity, a Pearson correlation of SPSS was also employed as presented in table 5 below.

Table 4. Correlation among the exogenous variables

\begin{tabular}{|l|c|}
\hline Correlations & SPSS \\
\hline Policy process<-- > Economic growth & .511 \\
Economic growth <-- > Scheme design & .578 \\
Economic growth <-- > Mobilization & .411 \\
Scheme design < -- > Mobilization & .482 \\
Mobilization < -- > Policy process & .434 \\
Policy process <-- > Scheme design & .456 \\
\hline
\end{tabular}

From the table above, it is evident that none of the variables are highly correlated with any other variables. For example, based on the Pearson Correlation among other variables range from 0.305-0.532. Specifies that all the correlation values are well below the yardstick of 0.9 and above, we could then conclude that there is no problem of multicollinearity among the variables under examination (Hair et al., 2010).

\subsection{EFA for Exogenous Variables}

In this study all the items constituting the exogenous variables (independent and dependent variables) were subjected to PCA using SPSS software (Bryn, 2010, Hair et al., Raykov \& Marcoulides, 2006). The notion became essential despite the measures were adopted from previous research; conversely, the measures were not only used in diverse background, but were were also made to order and costume the research goals. Furthermore, Kaiser-Meyer-OLkin (KMO) measure of sampling adequacy was 0.810 far above the recommended value of 0.6 (Maiyaki \&Moktar, 2011; 
Kaiser, 1970, 1974). In line with the recommendation of Kaiser (1974). Therefore, the value of .810 in this study is great values and hence, the data are considering fitting for factor analysis.

Similarly, in this study the Bartlett's Test of Sphericity was revealed to be statistically significant at $P>0.001$ sustaining the factorability of correlation matrix. The result indicates that there exist some associations surrounded by the variables under investigation. PCA reveals the presence of eight components with Eigen values of above 1 explaining the cumulative variance of $67.7 \%$. In addition, communalities in this study signify the amount of the variance in the original variables that is accounted for by the factor solution. Hence, the factor solution should give details at least half of each original variable's variance, so the communality value for each variable should be 0.50 or higher (Kaiser, 1974). Therefore, a good number of the items show simple structures by loading highly on only one component; however, a few items in addition, the items have communality below 0.5 ; have been considered for deletion during Confirmatory Factor Analysis (CFA) and consistent with (Gorondutse \& Hilman, 2014;Maiyaki \& Mouktar, 2011). Table 6 below shows the factor loadings and communality values for each item (see Table 6).

Table 6. Factor loading and communality for exogenous variables

\begin{tabular}{|c|c|c|}
\hline Items & Loadings & Communality \\
\hline PP1 & .662 & .427 \\
PP2 & .710 & .508 \\
PP3 & .666 & .444 \\
PP7 & .525 & .299 \\
PP12 & .757 & .599 \\
PP13 & .853 & .741 \\
PP14 & .807 & .655 \\
EG1 & .814 & .675 \\
EG2 & .796 & .675 \\
EG3 & .851 & .732 \\
EG5 & .779 & .634 \\
SD1 & .843 & .715 \\
SD2 & .801 & .687 \\
SD3 & .620 & .447 \\
SD4 & .702 & .497 \\
SD5 & .753 & .568 \\
SD6 & .600 & .385 \\
MOB1 & .882 & .777 \\
MOB2 & .870 & .760 \\
MOB3 & .524 & .295 \\
MOB10 & .765 & .601 \\
MOB11 & .773 & .616 \\
\hline
\end{tabular}

Extraction Method; Principal Component Analysis

\subsection{EFA for Endogenous Variables}

Similar to exogenous variables, all the constructs and items that constitute endogenous variables were subjective to principal Component Analysis with the aid of SPSS software (Hair et al., 2010). The preliminary analysis reveals that the data is fitting for factor analysis. For example, a visual examination through the correlation matrix reveals that the numerals of coefficients have values of 0.3 and above thus fulfilling the first requirement. Furthermore, by observing the correlation matrix again, no value was found to be 0.9 or above, thereby satisfying that the data is free from the multicollinearity dilemma (Gorondutse \& Hilman, 2014;Kaiser, 1974; Maiyaki \& Moktar, 2011). Similarly, the result of Kaiser-Meyer-Olkin (KMO) measure of sampling adequacy Kaiser, (1974) was 0.812 which above the recommended 0.6 and could be regarded as great (Hair et al., 2010; Kaiser, 1974). In addition, the Bartlett's Test of sphericity is significant at $\mathrm{P}<0.001$ which supports the factorability of correlation matrix. Moreover, the cumulative total variance explained by the mechanism is $54.966 \%$, which is relatively rational (Gorondutse \& Hilman, 2014; Hair et al., 2010 Kaiser, 1974). In addition, with regards to communality most of the items have values of 0.5 and above except ( PP1 .427; PP7 .299; SD3 .447; SD6 .385; MOB3.295). So items were marked for deletion in the subsequent analysis. Table 7). 
Table 7. Factor loading and communality for endogenous variables

\begin{tabular}{|c|c|c|}
\hline Items & Loading & Communality \\
\hline IMPACT3 & .992 & .991 \\
IMPACT4 & .664 & .441 \\
IMPACT5 & .601 & .408 \\
IMPACT6 & .749 & .363 \\
IMPACT7 & .749 & .585 \\
IMPACT8 & .707 & .508 \\
\hline
\end{tabular}

Extraction Method: Principle Component Analysis.

\section{Conclusion}

Based on the results in the study it shows that there are small amount of missing values have been replaced using mean value replacement as suggested by Hair et al. (2010), since the value is less than $5 \%$. Similarly, the univariate and multivariate outliers were removed in line with (Hair et al., 2010; Tabachnick \& Fidell,2007), as a results the data established to be normally spread and also there was no dilemma of non response bias, consequently, it could be the absolute state that the data is completely screened and cleaned ready for multivariable analysis (Hair et al., 2010; Tabachnick \& Fidell, 2007). In addition, the convergence of most of the factors into different components with high factor loadings confirms that the variables are actually measuring different constructs as hypothesized. This is in line with the result of multicollinearity which was found to be absent (Gorondutse \& Hilman, 2014; Hair et al., 2010; Tabachnick \& Fidell, 2007). Therefore, the above results it is hereby confirmed that the data has deserved the most imperative postulations and needs to the stage multivariate analysis. Thus, the findings will give an insight to further analysis its hope to provide an understanding of how and why this may be diversified in a perspectives rising environment.

\section{References}

A.S. Preker. (2002). Effectiveness of Community Health Financing in Meeting the Cost of Illness. Bulletin of the WHO, 80(2), 143-150. Anderson, N., \& Marks, S. (1987). Work and health in Namibia: preliminary notes. Journal of Southern African Studies, 13(2), $274-292$.

Atim, C. (1998). Contribution of Mutual Health Organization to Funding, Delivery and Access to Health Care: Synthesis of Research in nine West's and Central African Countries.

Atim CB, Diop FP, E. J. et al. (1998). The Contribution of Mutual Health Organizations to Financing, Delivery, and Access in Health Care in West Africa: Summaries and Case Studies in Six Countries. Doi:No 19

Bennett S, Creese A, M. R. (1998). Health Insurance Scheme for People Outside Formal Sector Employment. Geneva.

Criel, B. (n.d.). District-Based Health Insurance in Sub-Saharan Africa. Part 1: Case-Studies. Studies.

Debaig, G. /cidr. (1999). Report on the Community Based Health Insurance Regional Conference in Kampala, Uganda. Kampala, Uganda.

Delgado-Gaitan, C. (2001). The Power of Community: Mobilization for Family and Schooling.

Dror, D.; Preker, A. S. (2002). Introduction, in Dror and Preker edited Social Re Insurance: A New Approach to Sustainable Community Health Financing.

Gilson, L., and A. M. (1995). Health sector Reforms in Sub-Saharan Africa: Lesson of the Last 10 Years. Health Policy, 32(1-3), 215-43.

Gilson, L., S. Russell, and K. B. (1995). The Political Economy of Financing Policy. Journal of International Development, 7(3), 369-402.

Gorondutse, A. H., \& Hilman, H. (2014). Effect of Business Social Responsibility (BSR) on Performance of SMEs: Data Screening and Preliminary Analysis, Asian Social Science, 10(8), 103-115,

Hair, J. F., Hult, G. T. M., Ringle, C. M., \& Sarstedt, M. (2013). A premier on partial least squares structural equation modeling (PLSSEM). SAGE Publication.

Hair, Jr. J. F., Black, W.C., Babin, B. J., \& Anderson, R. E. (2010). Multivariate data analysis (Vol. 7th ed.). Upper Saddle River, New Jersey.

Kaiser, H. F. (1974). A second generation Little Jiffy, 35, 31-36. Retrieved from http://dx.doi.org/10.1007/BF02291575

Maiyaki, A. A., \&Moktar, s. s. m. (2011). Influence of service quality, corporate image and perceived value on customer behavior responses in Nigerian Banks: Data screening and preliminary analysis. In International Conference on Management Proceeding (pp. 547-568).

Morrison, C. (2002). Health, Education and Poverty Reduction, OECD Policy Brief.

Mugisha F, Kouyate B, Dong H, S. R. (2009). Costing Health Care Interventions at Primary Health Facilities in Nouna, Burkin Faso. African Journal of Health Sciences, 9, 63-73.

Musau S. (1999). Community Based Health Insurance: Experiences and Lessons Learned from East and Southern Africa. doi:NO .34

Musau, S. (1999). Community-Based Health Insurance: Experience and Lessons Learned from East Africa. N.

Salihu. A. Adedibu. (2011). Service Delivery by Local Government in Nigeria: The Delivery of primary Education and Healthcare Service 
by Local Government in Nigeria.

Sheik, K. (1981). Investigating non- response bias in mail surveys. Journal of Epidemiology and Community Health., 35, $293-296$. Retrieved from http://dx.doi.org/10.1136/jech.35.4.293

Sheth, K. (2013). Evaluating Health-seeking Behavior, Utilization of care, and Health Risk: Evidence from a Community Based Insurance Model in India.

Singer, E. (2006). Non-response bias in household surveys. Public Opinion Quarterly, 70(5), 637-645. Retrieved from http://dx.doi.org/ 10.1093/poq/nf1034

Tabachnic, B. G, \& Fidell, L. S. (2007). Using multivariate statistics (5th ed.). Boston: Pearson Education Inc.

Usoroh, E. E. (2012). Achieving Universal Health Coverage in Nigeria: The National Health Insurance scheme as a Tool., 16-17.

WHO. (1989). Community Involvement in Health Development: An Examination of the Critical Issues.

WHO. (1998). 1998 World Report. Geneva.

WHO. (2000). World Health Report 2000- Health Systems: Improving Performance.

WHO. (2002). WHO Country Cooperation Strategy: Federal Republic of Nigeria 2002-2007.

WHO. (2005). The World Health Report: Make Every Mother and Child Count. Geneva.

WHO. (2009). WHO Country Co-operation Strategy 2008-2013: Nigeria Republic of Congo:, P.8. 